\title{
Estado da arte da pesquisa acadêmica sobre prêmios em Jornalismo Robson Dias
}

\section{Resumo}

Os prêmios em Jornalismo são elementos constituintes da cultura profissional que incidem de forma indireta sobre o processo de produção $d a$ notícia (Molotch and Lester). Apesar da quantidade de premiações editadas, elas não são muito estudadas pela ciência, em Comunicação. Neste artigo, há o esforço em compilar os trabalhos sobre o tema nas décadas de 1990, 2000 e de 2010, em todo o território nacional, com o intuito de construir uma referência para pesquisadores interessados no tema. 0s estudos da revisão bibliográfica versam sobre prêmios em Jornalismo Investigativo, Jornalismo Institucional e Fotojornalismo.

\section{Palavras-Chave}

Jornalista. Meritocracia. Prêmios. Newsmaking.
Robson Dias ${ }^{1}$ | rbsn.dias@gmail.com Doutor em Comunicação pela Universidade de Brasília (UnB). Vínculo institucional à Universidade Católica de Brasília (UCB)

\section{Introdução}

Os prêmios em Jornalismo figuram como elementos de normatividade e prescrição de ethos, valores e procedimentos na cultura profissional jornalística. As organizações que editam premiações podem ser entendidas como definidores primários não somente no processo de produção da notícia e nas rotinas produtivas (modo direto), mas também das chancelas de mérito jornalístico por meio dos prêmios na cultura profissional (modo indireto), influenciando o jornalista na questão do que é ou não notícia (news judgement) (1993, p. 85). A partir da certificação premiativa, que prescreve o "profissionalismo" como "método de controle do trabalho" (TRAQUINA, 2001, p. 107), dando 0 status de bom ou mau jornalismo, há o explícito reconhecimento do domínio das técnicas do fazer, além do saber, como procedimento jornalístico. Mas, tacitamente, também há a doutrinação da subjetividade dos jornalistas.

Frequentemente, nos estudos de Agendamento e Newsmaking, fala-se muito de como os definidores primários (HALL et al, 1993) 
agem em relação às rotinas produtivas

(TUCHMAN, 1993) no cotidiano profissional, mas não se comenta muito sobre as rotinas cognitivas (SOUSA, 2003) ou limites cognitivos (TRAQUINA, 1993) relativos à subjetividade de cada jornalista. 0 que valida não apenas 0 doutrinamento da pauta das redações (rotinas produtivas), mas a cosmovisão dos jornalistas (rotinas cognitivas).

As organizações tendem a influenciar diretamente o processo de produção da notícia (MOLOTCH e LESTER, 1974) e as rotinas produtivas (TUCHMAN, 1978), mas também influenciam indiretamente ao apontar para a subjetividade do indivíduo (cosmovisão do jornalista) na cultura profissional (SCHUDSON, 1993; HALL et al, 1993).

A cultura profissional é um complexo emaranhado de retóricas de fachada e astúcias táticas, de códigos, estereótipos, símbolos, tipificações latentes, representações de papéis, rituais e convenções, relativos às funções dos mass media e dos jornalistas na sociedade, à convenção do produto-notícia e às modalidades que superintendem a sua confecção (WOLF, 2001, p. 189). Sendo que o profissionalismo controla o comportamento dos jornalistas de dois modos relacionados: estabelecendo padrões de conduta e normas de comportamentos (1), e determinando o sistema de recompensa profissional (2) (SOLOSKI, 1993, p. 95). 0 primeiro aspecto, dos padrões de conduta e normas de comportamentos, é relativo à atuação indireta dos definidores primários frente a dissonâncias cognitivamente induzidas nos jornalistas em suas redações e rotinas produtivas. Dentro do cotidiano de produção da notícia de cada profissional, existem as rotinas cognitivas: percepções que o jornalista tem da realidade, podendo, posteriormente, favorecer a avaliação do que é noticioso, além do fato de as rotinas produtivas estarem confinadas nos limites cognitivos da racionalidade (1993, p. 93).

E o segundo aspecto, sobre o sistema de recompensa profissional, trata da questão do prêmio como substantivo, no sentido dicionarizado: recompensa, bônus, agrado,

Doutor em Comunicação, formado pela Universidade de Brasília (Programa de Pós-Graduação da Faculdade de Comunicação, PPGFAC/UnB) a partir do vínculo com os seguintes projetos de pesquisa credenciados no CNPQ: A ideia do pós-Jornalismo (20102013), O Jornalismo como Teoria Democrática (2006-2010) e Como o Terceiro Setor pauta a mídia (2003-2006). Atualmente, é professor titular do mestrado Stricto Sensu em Comunicação da Universidade Católica de Brasília (PPGSSCOM/UCB), linha Processos Comunicacionais nas Organizações.

A revisão e problematização apresentada no artigo são constituintes da tese Prêmios em Jornalismo: paradigmas em transição, elaborada sob a orientação da Prof. Dr. Luiz Martins da Silva. Na pesquisa, o autor investigou 114 prêmios na cultura profissional do Jornalismo e mapeou este universo em 30 categorias, propondo teoricamente a figura dos News Honors, um lócus não visto ainda na Teoria da Notícia, na qual se enquadram os agentes que promovem indiretamente a normatização das rotinas produtivas por meio dos prêmios, no tocante aos limites cognitivos de Traquina (1993) e às rotinas cognitivas de Sousa (2003), somando este novo dispositivo ao processo de produção da notícia, classificados em Molotch e Lester (1974), como: News Promoters, News Assemblers e News Consumers. 0 autor recebeu bolsa de pesquisa em doutorado da Coordenação de Aperfeiçoamento de Pessoal de Nível Superior (Capes). 
galardão, ou seja, aquilo que se ganha (simbólica ou materialmente) ao chegar a um objetivo.

Os prêmios em Jornalismo operam em relação a diversos conceitos identificados em Teorias da Comunicação, tais como: controle do seu trabalho (Breed) nas rotinas produtivas (Tuchman), a questão da ação pessoal e seleção de notícias (Lewin) por um filtro (White, Senra), o profissionalismo (Soloski), sofrimento com a pressão do tempo (Schlesinger), relacionamento entre fontes e os jornalistas (Molotch e Lester), além de questões relativas à visão de mundo $\mathrm{e}$ cultura profissional (Schudson, Hall et al).

A partir desse quadro teórico, cita-se a produção científica em Comunicação, no Brasil, sobre prêmios em Jornalismo, sendo composta por: Cassol (1997), Santos (2004), Magno (2006), Passos (2007), Mora (2008), Dias (2008), Gonçalves (2010), Castilho (2010) e Dias (2013).

Cronologicamente, como marco inicial dos estudos sobre prêmios em Jornalismo, na década de 1990, surge a primeira dissertação na área de Comunicação a respeito do assunto: Prêmio Esso e as transformações da reportagem (CASSOL, 1997).

Na década de 2000, há um crescimento de 600\%, com as dissertações Um estudo das fotos vencedoras do prêmio Vladimir Herzog de Anistia e Direitos Humanos (SANTOS, 2004); A agonia da reportagem: das grandes aventuras da imprensa brasileira à crise do mais fascinante dos gêneros jornalísticos: uma análise das matérias vencedoras do Prêmio Esso de Jornalismo (MAGNO, 2006); A Produção de Efeitos de Sentido nas Fotografias de Imprensa Brasileira: Análises Técnicas, Plásticas e Semânticas (PASSOS, 2007); Houseorgans: da teoria à prática (CARVALHO, 2007); Cidadania em Pauta: O Concurso Tim Lopes de Investigação Jornalística como estratégia de agendamento da violência sexual contra crianças e adolescentes na imprensa brasileira (MORA, 2008) e A influência do prêmio Jornalista Amigo da Criança sobre o profissional de jornalismo: estudo de caso (DIAS, 2008).

Na década de 2010, ao avançar no tratamento dado ao tema, saindo da tônica de abordar os vencedores dos prêmios, surgem as duas primeiras teses sobre 0 assunto: Um patrimônio dos próprios jornais - as escolhas do campo jornalístico sob a ótica do Prêmio Esso (CASTILHO, 2010) e Prêmios em Jornalismo: paradigmas em transição (DIAS, 2013), além de uma dissertação que estudou jornalistas ganhadores de prêmios sem estar em redações tradicionais, mas em redações corporativas: $O$ super-homem pendura o paletó na repartição: a gênese do jornalista legislativo (GONÇALVES, 2010).

Em 15 anos, oito dissertações e duas teses foram elaboradas sobre 0 tema, sendo a maioria relativa aos vencedores dos prêmios (70\%), nos estudos de caso das dissertações. E o restante foi sobre 
questões identitárias da profissão de jornalista que emergem das premiações (30\%).

Recentemente, em 2011, surge uma iniciativa fora do âmbito da ciência, mas com uma abordagem própria de estudo dos prêmios: o Centro de Memória dos Prêmios de Jornalismo do Brasil (apoiado e financiado por Shell, Gerdau, Ambev, Embraer), que faz o Ranking Jornalistas\&Cia, com base em quase 70 prêmios em Jornalismo, nacionais e estrangeiros. 0 ranqueamento leva em conta uma metodologia institucional de escala de notas, critérios de pontuação, além da incorporação de dados de outros rankings nacionais e regionais, em vários anos. E conta com 0 arquivo de regulamentos e dados sobre prêmios em todo o país.

Nas próximas seções deste artigo, a abordagem trata como os prêmios são estudados em outras áreas do conhecimento para, depois, retomar os pesquisadores em Comunicação, além da iniciativa do Centro de Memória dos Prêmios de Jornalismo do Brasil. Também há a contextualização temática e teórica na qual se insere 0 estudo dos prêmios na Comunicação, a partir do mapeamento do conhecimento científico em Strelow (2011).

\section{Os prêmios como objeto de estudo na ciência}

Na ciência, não há uma tradição para estudo de prêmios com uma abordagem formal dos trabalhos como se existisse uma pretensa "teoria premiativa”, mas há abordagens sobre mérito, ethos e procedimentos. Em sua maioria, costumam utilizar a questão simbólica (em Bourdieu como Poder Simbólico e Sistema de Trocas Simbólicas), além da meritocracia (em Weber, sobre o poder do mérito nas hierarquias institucionais).

Na Administração, por exemplo, é muito comum trabalhos que avaliem os resultados de rotinas administrativas e burocráticas, além do recrutamento de profissionais com perfil exemplar: $O$ Aprendizado nas Organizações Vencedoras do PNQ - Prêmio Nacional de Qualidade (GUARAGNA, 2004); A Institucionalização da Gestão e do Desempenho Organizacional por meio do Prêmio Nacional da Qualidade (AIDAR, 2003); Os Prêmios da Qualidade como Modelos de Diagnóstico em Serviço - Um Estudo de Caso no Ensino Público (HIENE, 2002); Relações Premiadas e sua valoração probatória (SIMIONE, 2001); A Verificação da Eficiência nas Organizações Governamentais (CIRILO, 2000); Competências Empreendedoras e Focos Comportamentais: Estudo de Casos dos Empreendedores das Empresas Ganhadoras do Prêmio Top Empresarial 2006 e 2007 (DIAS, 2009). Já na Economia, percebe-se uma abordagem dos prêmios com relação ao controle de qualidade de serviços e produtos: Prêmio pelo risco cambial: uma análise comparativa com moedas da América Latina (IVERSSON, 2009); 
Avaliação dos prêmios de tamanho e controle nas fusões e aquisições de empresas no Brasil (MACEDO, 2009); Prêmio de controle no Brasil (FERNANDEZ, 2008), Testando a existência de prêmio de volatilidade e ações líquidas da Bovespa (CUNHA, 2008).

\section{Na pesquisa em Comunicação, onde se situam os prêmios em Jornalismo?}

Strelow (2011), em $O$ estado da arte da pesquisa em jornalismo no Brasil: 2000 a 2010, mapeou o conhecimento em artigos científicos sobre Jornalismo publicados em revistas acadêmicas nacionais listadas pelo sistema Qualis, da Coordenação de Aperfeiçoamento de Pessoal de Nível Superior (CAPES), instituído nos primeiros anos da década. Com isso, teve um índice de frequência dos temas de pesquisa, campos teóricos e métodos mais utilizados no arcabouço teórico da Comunicação, no Brasil, em um universo de 853 pesquisas. 0 mapeamento da autora é em cima de artigos científicos, mas utilizaremos os rankings criados por ela, para tentar contextualizar onde 0 estudo dos prêmios em Jornalismo toca a ciência em Comunicação (a seguir, em negrito).

Strelow (2011) faz um ranking dos temas mais estudados entre 2000 e 2010, no Brasil, em categorias aglutinadoras do conhecimento criadas por ela: Jornalismo Especializado (1); Teorias do Jornalismo (2); Estudos de Linguagem (3); Jornalismo Digital (4); Jornalismo e representação (5); Rotinas Jornalísticas (6);

História do Jornalismo (7); Telejornalismo

(8); Jornalismo e sociedade (9); Ética jornalística (10); Pesquisa em Jornalismo (11); Fotojornalismo (12); Transformações no jornalismo (13); Radiojornalismo (14); Ensino do jornalismo (15), Jornalismo e recepção (16).

Os prêmios em Jornalismo, se enquadrados na avaliação temática de Strelow (2011), estão contidos principalmente nas categorias: rotinas produtivas e transformações no jornalismo, sendo o $6^{\circ}$ e 0 $13^{\circ}$ tema mais estudado, respectivamente.

Strelow (2011) também faz um ranking de campos teóricos mais recorrentes nas pesquisas em Comunicação, sendo eles: História do Jornalismo (1); Discurso (2); Estudos Culturais (3); Semiótica/Semiologia (4); Newsmaking (5); Jornalismo Digital (6); Sociologia do Jornalismo (7); Epistemologia do Jornalismo (8); Teoria Construcionista (9); Convergência midiática/Novas mídias (10); Ética Jornalística (11); Narrativa Jornalística (12); Agenda Setting (13); Enquadramento (14); Teorias da Ação Política (15); Rotinas Jornalísticas (16); Telejornalismo (17); Jornalismo como forma de conhecimento (18); Jornalismo literário/Jornalismo (19); Literatura Jornalismo Cultural (20); Economia Política da Comunicação (21); Teoria Crítica (22); Critérios de Noticiabilidade (23); Estudos de Recepção (24); Gatekeeping (25); Linguagem Jornalística (26); Ensino do Jornalismo (27); 
Fotojornalismo (28); Jornalismo Científico

(29); Teorias da Representação (30); Campos

Sociais (31); Cultura Jornalística (32); Gêneros jornalísticos (33), Interacionismo Simbólico

(34). A partir dessa avaliação teórica da autora, relativa a campo teórico, podemos enquadrar os prêmios posicionados dentro das categorias de cultura jornalística ( $32^{\circ}$ no ranking da autora) e rotinas jornalísticas $\left(16^{\circ}\right)$, constituintes de um campo mais amplo: Newsmaking $\left(5^{\circ}\right)$.

Esse posicionamento, que ora se faz dentro das categorias de Strelow, serve para afirmar o seguinte: os prêmios não são um assunto tão novo, no sentido conceitual. Os prêmios são novos como objetos de estudo no Jornalismo e como elementos levados em conta no processo de produção da notícia. Neste artigo, não se discorre sobre uma nova linha de conhecimento com uma "teoria premiativa" da notícia. Mas, classifica-se o estudo dos prêmios dentro dessas categorias de conhecimento citadas no intuito de auxiliar com uma revisão bibliográfica, leitores e pesquisadores interessados na área.

\section{Quem são os estudiosos sobre prêmios em Jornalismo?}

Na Comunicação, apesar de existirem autores que tratem especificamente dos constrangimentos organizacionais (Soloski) e controle do trabalho (Breed), este tipo de abordagem não é muito vinculado aos estudos dos prêmios em Jornalismo, que versam tradicionalmente sobre questões de valores-notícias e de vencedores das premiações. Este panorama começa com Cassol (1997), ainda na década de 1990. Esta dissertação pioneira estudou vencedores do Prêmio Esso de Jornalismo na região Sul do país, fazendo apontamentos sobre transformações da reportagem, vinculando-as à evolução do Jornalismo Impresso no contexto brasileiro. Este trabalho associava muito 0 prêmio em questão à modalidade de Jornalismo Informativo, de origem norte-americana, com a prescrição da impessoalidade, imparcialidade e isenção aos jornalistas, além de técnicas baseadas no referencial de Objetividade, como o lead, copy desk e a pirâmide invertida.

Apesar do valor das conclusões de Cassol (1997), nos anos 1990, quase uma década depois, nenhum trabalho científico havia sido elaborado em relação a premiações no país na área de Comunicação. 0 quadro mudou a partir de trabalhos como o de Santos (2004), que estudou fotografias vencedoras do Prêmio Vladimir Herzog de Anistia e Direitos Humanos, em uma abordagem semiótica, traçando uma retrospectiva da história e importância do advento da fotografia para a sociedade em relação à afirmação histórica dos direitos humanos, passando pela circunstância política que provocou a morte do próprio jornalista Vladimir Herzog, em 1975. Trata-se do único trabalho sobre este prêmi ${ }^{2}$. Santos (2004) também inaugura o estudo de prêmios relativos ao Terceiro Setor, contexto conhecido em organizações da Sociedade Civil pós-neoliberalismo. 
Também deve ser citada Magno (2006), que classificou as matérias ganhadoras do Prêmio Esso de Jornalismo, de 1956 a 2005, e verificou mudanças no perfil dos gêneros jornalísticos e preceitos relativos à Objetividade em 50 anos de premiação. A autora nota mudanças significantes, a partir do Prêmio Esso, na tipologia de Jornalismo Investigativo, a julgar pelos vencedores da premiação, em 51 anos (1955-2006), tais como: não há mais reportagens sociais, a julgar pelo gênero de reportagem. Em sua pesquisa, ela demonstra que apenas quatro exceções não se enquadram neste diagnóstico, sendo a ênfase das reportagens premiadas pelo Prêmio Esso (ou o "único tema premiado na categoria principal") a corrupção política no Legislativo, no Executivo e no Judiciário (concentrada em São Paulo, no Rio de Janeiro e em Brasília). A autora trabalha a questão de a reportagem ter se especificado no país como um gênero tipicamente denuncista.

A pesquisa de Passos (2007), que estudou os vencedores do Prêmio Esso de Jornalismo na categoria Fotojornalismo e a produção de efeitos de sentido codificado (ou não) de sua amostra, em uma abordagem semiótica que versava sobre estética e linguagem, traça uma evolução histórica da fotografia no Jornalismo ao interpretar elementos até chegar a marcas da enunciação nas mensagens fotográficas vencedoras da premiação.
A abordagem final de seu trabalho é sobre estética, mas ele aborda a fotografia em Jornalismo como prática exemplar, o que valida a questão premiativa em apreço. Passos (2007) é o segundo a tratar dos prêmios relativos ao Fotojornalismo, como abordado em Santos (2004), anteriormente.

Dias (2008) estudou a influência do Prêmio Jornalista Amigo da Criança, em meio a 346 profissionais premiados, como estratégia de agendamento de pautas, mudança nas rotinas produtivas, além do engajamento de jornalistas em defesa e promoção dos direitos da criança e do adolescente. 0 mote do trabalho era ver se os jornalistas certificados como amigos da infância realmente se sentiam motivados nesta missão e quais as mudanças identitárias para esses profissionais. A abordagem leva em conta uma especificidade de prêmios voltados para profissionais e não para matérias ou empresas. É uma pesquisa em prêmios oriundos do Terceiro Setor que amplia a abordagem de premiações deste universo iniciada em Santos (2004).

\section{Mora (2008) estudou o Concurso Tim Lopes de Jornalismo, uma premiação que certifica não as melhores reportagens pós-veiculação na mídia, mas premia pautas que concorrem a uma verba institucional para produção de uma reportagem financiada pela premiação, em uma perspectiva pré-veiculação na mídia. A}


autora identifica diferenças em prêmios de nome parecido: Concurso Tim Lopes de Jornalismo Investigativo (Agência de Notícias dos Direitos da Infância, ANDI) e Prêmio Tim Lopes de Jornalismo Investigativo (Rede Globo). A contribuição para a comunidade científica é 0 de identificar os dois prêmios trabalhando com a questão do Jornalismo Investigativo, mas um premia a matéria pré-produção (a pauta) e 0 outro, a matéria pós-produção (depois de veiculada na mídia). E cita a questão de ambos os paradigmas fomentarem a investigação jornalística, mas o paradoxo de se premiar a pauta (pré-produção) ou a matéria veiculada (pós-produção), o que gera discussão sobre a reportagem investigativa paga (ou não). Mora (2008) apresenta mais dados sobre prêmios oriundos do Terceiro Setor, ampliando a abordagem de premiações deste universo iniciada em Santos (2004).

Gonçalves (2010) estudou a especificidade de jornalistas que abandonaram as redações e assumiram cargos públicos em repartições públicas, dando início ao que ele chama de jornalista legislativo, na perspectiva de Mídia das Fontes e de Jornalismo Corporativo ${ }^{3}$. 0 autor listou 26 prêmios nacionais e internacionais que estes profissionais com status de jornalistas legislativos ganharam, mesmo não estando em redações da mídia tradicional, mas ocupando postos de trabalho na estrutura organizacional da administração pública federal. Tal fato mostra que o Jornalismo Institucional pode fazer notícia e competir com profissionais do mercado noticioso das grandes corporações, na perspectiva de Mídia das Fontes e Jornalismo Corporativo. Seu estudo é paradigmático por abordar jornalistas que estão dentro das organizações e recebem prêmios de Jornalismo concorrendo de igual para igual com repórteres do mercado tradicional. E é o primeiro estudo a versar sobre mais de um prêmio, tendo compilado 25 premiações em seu corpus.

Castilho (2010) investigou o Prêmio Esso de Jornalismo, edições de 1964 a 1978, e as implicações na identidade profissional do jornalista brasileiro durante o Regime Militar. 0 autor estudou a premiação desde a instauração do regime (1964-1968), período de controle mais rigoroso da censura (1968-1975), até o início da abertura política (1975-1978), a partir de entrevistas com membros do júri e jornalistas premiados em algumas edições desses três períodos. E tem o prêmio como patrimônio dos jornalistas, a partir da importância para a estruturação da identidade jornalística, no Brasil, a partir da premiação fomentadora do modelo de Jornalismo Investigativo, principalmente durante 0 Regime Militar. Castilho (2010) também retoma a questão dos prêmios contextualizados na 
ditadura, conforme iniciativa vista anteriormente em Santos (2004).

Dias (2013) estudou 114 premiações em Jornalismo para matérias, profissionais e empresas de comunicação, classificandoas em 30 categorias. 0 autor trata como paradigma a questão de as premiações visarem à certificação não somente no Jornalismo Investigativo (denúncia), mas também no Jornalismo Institucional (promoção), além da mudança de foco em relação ao sujeito, com a tensão do jornalista interventor (ou não) na realidade: Jornalismo Informativo (isenção, imparcialidade, impessoalidade) e Jornalismo Público (advocacy, engajamento e mobilização social). E soma-se ao processo de produção da notícia News Promoters, News Assemblers e News Consumers, em Molotch e Lester (1974), a figura dos News Honors: um lócus não visto ainda na Teoria da Notícia, na qual se enquadram os agentes que promovem a normatização das rotinas produtivas por meio dos prêmios, no tocante aos limites cognitivos de Traquina (1993) e às rotinas cognitivas de Sousa (2003).

Cronologicamente, os estudos de prêmios em Jornalismo consistem em:

- Década de 1990: Cassol (1997).

- Década de 2000: Santos (2004), Magno (2006), Passos (2007), Dias (2008) e Mora (2008).
- Década de 2010: Castilho (2010), Gonçalves (2010) e Dias (2013).

Tematicamente, há uma certa concentração sobre o Prêmio Esso, mas também abordagens feitas exclusivamente sobre outras premiações, como: Prêmio Jornalista Amigo da Criança, Concursos Tim Lopes de Jornalismo Investigativo e Prêmio Vladimir Herzog de Anistia e Direitos Humanos. Há ainda pesquisas que versam sobre diversos prêmios simultaneamente.

Quanto a modelos de Jornalismo, Cassol (1997), Magno (2006) e Castilho, (2010) ao abordarem o Prêmio Esso de Jornalismo, se dedicaram a investigar uma premiação que validava a modalidade de Jornalismo Investigativo, com todos os preceitos inerentes ao referencial de Objetividade. Já os trabalhos de Dias (2008) e Nora (2008), Prêmio Jornalista Amigo da Criança e Concurso Tim Lopes de Jornalismo, respectivamente, tinham mais contato com prêmios que operam com um jornalista engajado em lutas sociais de promoção da cidadania, associados à modalidade de Jornalismo Público. Santos (2004) e Passos (2007) concentraram esforços no Fotojornalismo.

Existe um trabalho em Comunicação, elaborado por Carvalho (2007), que não é citado aqui porque sua abordagem é em Relações Públicas. 0 autor estudou os House Organs vencedores do Prêmio Aberje, na perspectiva de Comunicação Interna (RP) e na perspectiva de Comunicação 
Empresarial (e não de Jornalismo

Institucional, Jornalismo Empresarial ou Jornalismo Corporativo).

Geograficamente, se mapeados os centros de pesquisa que originaram os estudos, tem-se: dois na Região Sul (1997 e 2006), quatro no CentroOeste (2006, 2008, 2010 e 2013) e três no Sudeste $(2004,2007 \text { e } 2010)^{4}$.

Em termos de crescimento, o tema dos prêmios em Jornalismo saltou de apenas um estudo para nove pesquisas, em 16 anos (1997-2013); um crescimento de 500\% na década de 2000 (em relação à década de 1990), e um acréscimo de 50\% na década de 2010 (em comparação à década de 2000), uma significativa contribuição com a ciência em Comunicação no país.

Recentemente, a iniciativa privada criou o Centro de Memória dos Prêmios de Jornalismo do Brasil, com o objetivo de fazer um ranking anual dos jornalistas mais premiados no país, além de servir de memória das premiações que têm certificado matérias, profissionais e empresas no mercado de Jornalismo e de Comunicação. A título de curiosidade, dos jornalistas brasileiros, Eliane Brum é considerada a mais premiada de todos os tempos no Ranking Jornalistas\&Cia.

Conclui-se essa breve revisão bibliográfica sobre 0 tema de prêmios em Jornalismo com a finalidade de fazer circular, em bases indexadas, o resultado dessas pesquisas, além de enunciados que possam ajudar outros pesquisadores a versarem sobre esse universo. Sabe-se que algumas pesquisas não são facilmente encontradas em bancos de dados de teses e dissertações. E muitas dessas pesquisas sequer viram publicações no mercado editorial. Em Jornalismo, muito se tem falado em modelos jornalísticos, tais como Jornalismo

\section{Informativo; Jornalismo Investigativo;}

Jornalismo Esportivo, Jornalismo Econômico e Jornalismo Científico, dentre outros. Mas pouco tem sido estudado neste universo, no sentido da cultura profissional, em detrimento do processo de produção da notícia e agendamento do noticiário. Esses estudos recentes sobre premiações tentam trazer novos elementos, práticas e conhecimento a este cenário. 0s autores citados não versam sobre uma nova Teoria do Jornalismo ou Teoria da Notícia, nem mesmo um rol específico como uma "teoria premiativa", "teoria da certificação de ethos" ou "teoria da meritocracia na midiocracia". Tais pesquisadores abordam elementos da cultura profissional pouco investigados ainda pela ciência em Comunicação no Brasil.

Aliás, essa palavra "cultura profissional" talvez seja a caixa de pandora ou um termo guardachuva, no qual se jogavam todas as coisas que saíam do foco do estudo dos emissores. A 
normatividade (preceitos, técnicas, cognição relativas ao processo de produção da notícia), dentro do sistema de premiações, é apenas mais um elemento compartilhado nesta cultura.

\section{Considerações Finais}

0 artigo tem um viés descritivo e quantitativo que, neste formato, pela limitante de caracteres, não pode explorar em mais seções as questões qualitativas deste universo dos prêmios, principalmente em relação aos dispositivos operacionais da pesquisa que dá origem a este estudo.

Em relação aos dois aspectos trabalhados na tese que alicerçam este artigo, padrões de conduta e normas de comportamentos (1) e 0 sistema de recompensa profissional (2), ressalta-se que os prêmios em Jornalismo são dispositivos utilizados pelos news promoters (Molotch e Lester) e definidores primários (Hall et al.), no intuito de acessar a cultura profissional (Schudson) e promover a certificação extraorganizacional de um ethos exemplar do que seria 0 bom e 0 mau, 0 êxito e 0 fracasso na profissão, nos moldes do profissionalismo (Soloski). Sousa (2002, p. 40) chama o universo da cultura profissional e extraorganizacional de fatores "ecossistemáticos" que levam os jornalistas, submetidos à pressão do tempo e a uma quantidade enorme de informações, a construírem rotinas cognitivas para organizálas. Assim, para 0 autor, ao adotarem formas rotinizadas e estereotipadas de pensamento,
0 jornalista tende a fabricar informação padronizada e a "selecionar sempre como tendo valor noticioso o mesmo tipo de acontecimentos". Ele conclui que, embora mescladas a outras forças, as notícias sempre têm algo da ação pessoal de quem as produz. A questão da cognição é tão importante, como medida para ganhar tempo nas redações e promover a formatação do texto noticioso e sua inteligibilidade, que Traquina (1993) trabalha a questão dos limites cognitivos em relação aos jornalistas diante do excesso de acontecimentos, quando as redações de grande porte recebem diariamente material suficiente para fechar diversas edições ao longo da semana e não um montante para apenas um dia. 0 autor fala dos limites cognitivos em vista dos critérios dos jornalistas na avaliação das fontes, além da dependência dos profissionais a esses fornecedores de matéria-prima.

É neste horizonte dos limites cognitivos de Traquina (1993) e das rotinas cognitivas de Sousa (2003) que, a partir do estudo de 114 premiações no Brasil e do levantamento do estado da arte no estudo sobre premiações nacionais, a tese que dá base aos insumos deste artigo mapeia 28 condições sobre as quais os prêmios se organizam, sendo elas: Quais setores mais realizam prêmios em Jornalismo? (1); Quais setores mais apoiam como parceiros prêmios em Jornalismo? (2); Formas de adesão do jornalista a prêmios (3); Cronologia dos prêmios mais antigos do país em anos de existência (4); Cronologia dos prêmios em número de edições (5); Abrangência 
Territorial dos prêmios (6); Quais são os tipos de recompensas oferecidas pelos prêmios? (7); Quem investe mais em dinheiro nos prêmios? (8); Quais os tipos de honrarias e distinções de mérito nos prêmios? (9), Quais setores premiam mais com ferramentas e financiamentos? (10); Menção Honrosa como prática exemplar não vencedora (11); Periodicidade dos prêmios (12); Existência (ou nãa) de taxa de inscrição (13); Registro legal dos regulamentos ou editais dos prêmios (14); Se as assessorias terceirizam (ou não) a realização dos prêmios (15); Aspectos quanto à soberania do júri (16); quanto à composição do júri (17); sobre controle externo via auditoria (18); sobre controle interno via instância recursal (19); Quem são os jornalistas premiados: profissionais ou estudantes? (20); Quais são os sindicatos e associações profissionais e patronais que apoiam as premiações? (21); Temas humanísticos mais utilizados (22); Temas globais mais utilizados como as 8 Metas do Milênio (23); Qual tipo de mídia é mais utilizado? (24); Quais os modelos jornalísticos mais utilizados? (25); A questão do direito autoral e patrimonial dos trabalhos (26); A apropriação de material para fins didáticos (27); Quais trabalham com responsabilidade legal relativo à questão do plágio? (28). Essas dimensões qualitativas podem ser de interesse do leitor, mas, por ora, não podem ser desenvolvidas neste formato de artigo devido à limitante dos caracteres e do presente gênero textual.

Sabe-se que muito do conhecimento científico gerado acaba ocupando prateleiras nas bibliotecas e tendo problemas de circulação da informação. Muitos trabalhos não são digitalizados nem de fácil acesso, o que leva o pesquisador a recorrer a estruturas de computação gráfica ou empréstimo direto da obra física. Também há o fato de alguns formatos digitalizados não circularem pelas bases indexadas e não se relacionarem com temas afins, figurando no espaço virtual apenas como um registro isolado e sem contato com informação similar. É neste sentido que 0 artigo propõe esta breve revisão bibliográfica. Acredita-se que 0 formato de artigo, em periódico científico, possa fazer circular resultados de pesquisas e referências sobre temas. É importante também ressaltar que o estudo de prêmios em Jornalismo faz com que se tirem do senso comum alguns discursos, seja nos centros acadêmicos ou até mesmo no mercado, que tendem a ter todas as premiações como iguais ou similares ao Prêmio Esso. Há muito a ser feito também nesta área, pois o foco tem sido principalmente 0 do estudo apenas das práticas exemplares: vencedores das premiações. Existem a possibilidade e a pertinência de abordagens sobre estratégias das organizações (1); organizações que propõem os prêmios (premiadores) (2); jornalistas vencedores dos concursos e os que são citados em menção honrosa, mas não são necessariamente vencedores (premiados) (3); os profissionais que concorrem nos certames (premiáveis), mas que não têm os trabalhos vencedores (4); a normatividade que emerge dos prêmios em relação ao processo de produção da notícia (5); sem falar nas estratégias que têm como foco 0 acesso 
não às redações, mas à cultura profissional (6). No artigo, propõe-se 0 "estado da arte" por força de expressão, mas a revisão bibliográfica, ora apresentada, valida-se como "estado da ciência" sobre os prêmios em Jornalismo.

\section{Referências}

BREED, W. Controle social na redação. Uma análise funcional. p.152-156. In TRAQUINA, N (Org.) Jornalismo: questões, teorias e estórias. Lisboa: Vega, 1993.

CARVALHO, Paulo. House-organs: da teoria à prática. (Dissertação, Mestrado em Comunicação). UMESP. 2007.

CASSOL, Ivone. Prêmio Esso e as transformações da reportagem. (Dissertação, Mestrado em Comunicação), PUC/RS. 1997.

CASTILHO, Marcio. "Um patrimônio dos próprios jornais" - as escolhas do campo jornalístico sob a ótica do Prêmio Esso. In: VII Encontro Nacional de História da Mídia, 2009, Fortaleza. VII Encontro Nacional de História da Mídia, 2009.

DIAS, Robson. Prêmios em Jornalismo: paradigmas em transição. (Tese, Doutorado em Comunicação), UnB. 2013

. Rol do mérito jornalístico: prêmios em Jornalismo e sua estruturação. Revista Brasileira de História da Mídia, v. 3, p. 95-103, 2014a. Disponível em: http://www.unicentro.br/rbhm/ed05/artigos/01.pdf . Acesso em 02/02/2014

Honra ao mérito: como a instituição do Prêmio Esso contribuiu para a adoção dos referenciais de objetividade jornalística no Brasil. Comunicação \& Inovação (Online), v. 15, n. 19, p. 126-137, 2014b. Disponível em: http://seer.uscs.edu. br/index.php/revista_comunicacao_inovacao/article/ view/2383/1585
Meritocracia do sujeito: prêmios em

Jornalismo pautados pela cidadania como flexibilização da objetividade jornalística. Revista Eletrônica do Programa de Pós-Graduação em Mídia e Cotidiano, v. 3, p. 414-431, 2014c. Disponível em: http://www. ppgmidiaecotidiano.uff.br/ojs/index.php/Midecot/ article/view/80. Acesso em 02/02/2014

\section{Prêmios em Jornalismo: a Cultura}

Meritocrática Premiativa dentro da Cultural Profissional Jornalística. Eptic (UFS), v. 16, p. 54-68, 2014. Disponível em: http://www.seer.ufs.br/index.php/ eptic/article/view/2275/1953 . Acesso em 02/02/2014

. Meritocracia na Midiocracia: reflexões sobre Prêmios em Jornalismo na cultura profissional jornalística. Revista FAMECOS (Online), v. 21, p. 525621, 2014d. Disponível em: http://revistaseletronicas. pucrs.br/ojs/index.php/revistafamecos/article/ view/17236. Acesso em 02/02/2014

Prêmios em Jornalismo: a emergência de um Novo Ethos Profissional. Comunicação \& Inovação (Online), v. 14, p. 1-50-56, 2013. Disponível em: http:// seer.uscs.edu.br/index.php/revista_comunicacao inovacao/article/view/1714/1388. Acesso em 02/02/2014

GONÇALVES, Rogério. 0 superhomem pendura o paletó na repartição: a gênese do jornalista legislativo. (Dissertação, Mestrado em Comunicação). UnB. 2010

HALL, Stuart, CHRITCHER, Chas, JEFFERSON, Tony et alii. A produção social das notícias: 0 "mugging" nos media. In: TRAQUINA, Nelson. (Org.) Jornalismo: questões, teorias e estórias. Lisboa, Vega, 1993.

MAGNO, Ana. A agonia da reportagem: das grandes aventuras da imprensa brasileira à crise do mais fascinante dos gêneros jornalísticos: uma análise das matérias vencedoras do Prêmio Esso de Jornalismo. (Dissertação, Mestrado em Comunicação, UnB). 2006.

MOLOTCH, Harvey e LESTER Marilyn. As notícias como procedimento intencional: acerca do uso 
estratégico dos acontecimentos de rotina, acidentes e escândalos. In: TRAQUINA, Nelson (org.) Jornalismo: Questões, teorias, estórias. Lisboa (Portugal) Vega. P.34-53.

MORA, Gabriela. Cidadania em Pauta: 0 Concurso Tim Lopes de Investigação Jornalística como estratégia de agendamento da violência sexual contra crianças e adolescentes na imprensa brasileira. (Dissertação, Mestrado em Comunicação), UNB. 2008.

PASSOS, Lucio. A Produção de Efeitos de Sentido nas

Fotografias de Imprensa Brasileira: Análises Técnicas, Plásticas e Semânticas. (Dissertação, Mestrado em Comunicação), Universidade do Tuiuiú. 2007.

SANTOS, Sandra. Um estudo das fotos vencedoras do prêmio Vladimir Herzog de anistia e direitos humanos. (Dissertação, Mestrado em Comunicação). USP. 01/06/2004

SOLOSKI, John. 0 jornalismo e o profissionalismo: alguns constrangimentos no trabalho jornalístico, in TRAQUINA, Nelson. Jornalismo: questões, teorias e estórias. Lisboa, Vega, 1993.

TRAQUINA, Nelson (org). 0 estudo do jornalismo no século XX. São Leopoldo, RS: Ed. Unisinos, 2001. . Jornalismo: Questões, teorias, estórias. Lisboa, Vega, 1999.

A Tribo Jornalística: uma comunidade transnacional. Lisboa (Portugal): Editorial Notícias, 2004a.

TUCHMAN, Gaye. A objetividade como ritual estratégico: uma análise das noções de objetividade dos jornalistas, in TRAQUINA, Nelson. Jornalismo: questões, teorias e estórias. Lisboa, Vega, 1993, P. 74-90.

WOLF, Mauro. Teorias da comunicação. Lisboa: Ed. Presença, 2001. 


\section{Journalism Awards} status in Brazilian Communication Research

\section{Abstract}

Prizes in Journalism are constituent elements of professional culture that focus indirectly on the News Process Production (Molotch and Lester). Despite the amount of awards issued, they are not much studied as main frame in Communication Research. In this article, there is an effort to overview this subject in 90's, 2000's and 2010's decades, throughout the national territory, in order to raise references to the academic scientists and researchers interested in Journalism Prizes and Awards. The literature review studies deal with prizes for Investigative Journalism, Corporate Journalism and Photojournalism.

\section{Keywords}

Journalist. Meritocracy. Awards. Newsmaking.
Premios de periodismo: la actualidad de la investigación académica brasilenã

\section{Resumen}

Premios de Periodismo son elementos constitutivos de la cultura profesional que se centran indirectamente en el proceso de producción de noticias (Molotch y Lester). A pesar de la cantidad de los premios otorgados, no están muy estudiados por la ciencia, en Comunicaciones. En este artículo, hay el esfuerzo de compilar las obra científicas sobre el tema en las décadas de 1990, 2000 y 2010, en todo el territorio brasileño, con el objetivo de construir una referencia para los investigadores interesados en premiaciones. La revisión bibliográfica de los estudios tratan de premios em las modalidads: Periodismo de Investigación, Periodismo Corporativo y Fotoperiodismo.

\section{Palabras-Clave}

Periodista. Meritocracia. Premios. Newsmaking. 


\section{Expediente}

A revista E-Compós é a publicação científica em formato eletrônico da Associação Nacional dos Programas de Pós-Graduação em Comunicação (Compós). Lançada em 2004, tem como principal finalidade difundir a produção acadêmica de pesquisadores da área de Comunicação, inseridos em instituições do Brasil e do exterior.

\section{E-COMPÓS I www.e-compos.org.br I E-ISSN 1808-2599}

Revista da Associação Nacional dos Programas

de Pós-Graduação em Comunicacão.

Brasília, v.17, n.3, set./dez. 2014

A identificação das edições, a partir de 2008

passa a ser volume anual com três números.

\section{CONSELHO EDITORIAL}

Afonso Albuquerque, Universidade Federal Fluminense, Brasil Alberto Carlos Augusto Klein, Universidade Estadual de Londrina, Brasil Alex Fernando Teixeira Primo, Universidade Federal do Rio Grande do Sul, Brasil Rio Grande do Sul, Brasi

Ana Gruszynski, Universidade Federal do Rio Grande do Sul, Brasil Ana Silvia Lopes Davi Médola, Universidade Estadual Paulista, Brasil André Luiz Martins Lemos, Universidade Federal da Bahia, Brasi Ângela Freire Prysthon, Universidade Federal de Pernambuco, Brasil Antônio Fausto Neto, Universidade do Vale do Rio dos Sinos, Brasil Antonio Carlos Hohlfeldt, Pontifícia Universidade Católica do Rio Grande do Sul, Brasil Antonio Roberto Chiachiri Filho, Faculdade Cásper Líbero, Brasi Arlindo Ribeiro Machado, Universidade de São Paulo, Brasil Arthur Autran Franco de Sá Neto, Universidade Federal de São Carlos, Brasil Benjamim Picado, Universidade Federal Fluminense, Brasil César Geraldo Guimarães, Universidade Federal de Minas Gerais, Brasil Cristiane Freitas Gutfreind, Pontifícia Universidade Católica do Rio Grande do Sul, Brasil Denilson Lopes, Universidade Federal do Rio de Janeiro, Brasil Denize Correa Araujo, Universidade Tuiuti do Paraná, Brasil Edilson Cazeloto, Universidade Paulista, Brasil

Eduardo Vicente, Universidade de São Paulo, Brasil

Eneus Trindade, Universidade de São Paulo, Brasil

Erick Felinto de Oliveira, Universidade do Estado do Rio de Janeiro, Brasil Florence Dravet, Universidade Católica de Brasilia, Brasil

Gelson Santana, Universidade Anhembi/Morumbi, Brasi Gilson Vieira Monteiro, Universidade Federal do Amazonas, Brasil Gislene da Silva, Universidade Federal de Santa Catarina, Brasil Guillermo Orozco Gómez, Universidad de Guadalajara, México Gustavo Daudt Fischer, Universidade do Vale do Rio dos Sinos, Brasil Hector Ospina, Universidad de Manizales, Colômbia Herom Vargas, Universidade Municipal de São Caetano do Sul, Brasil leda Tucherman, Universidade Federal do Rio de Janeiro, Brasil Inês Vitorino, Universidade Federal do Ceará, Brasil Janice Caiafa, Universidade Federal do Rio de Janeiro, Brasil Jay David Bolter, Georgia Institute of Technology, Estados Unidos Jeder Silveira Janotti Junior, Universidade Federal de Pernambuco, Brasi João Freire Filho, Universidade Federal do Rio de Janeiro, Brasil John DH Downing, University of Texas at Austin, Estados Unidos Ana Carolina Damboriarena Escosteguy, Pontifícia Universidade Católica do

José Afonso da Silva Junior, Universidade Federal de Pernambuco, Brasil José Carlos Rodrigues, Pontifícia Universidade Católica do Rio de Janeiro, Brasil José Luiz Aidar Prado, Pontifícia Universidade Católica de São Paulo, Brasil José Luiz Warren Jardim Gomes Braga, Universidade do Vale do Rio dos Sinos, Brasil Juremir Machado da Silva, Pontifícia Universidade Católica do Rio Grande do Sul, Brasil Laan Mendes Barros, Universidade Metodista de São Paulo, Brasi Lance Strate, Fordham University, USA, Estados Unidos Lorraine Leu, University of Bristol, Grã-Bretanha Lucia Leão, Pontifícia Universidade Católica de São Paulo, Brasil Luciana Panke, Universidade Federal do Paraná, Brasil Luiz Claudio Martino, Universidade de Brasília, Brasil Malena Segura Contrera, Universidade Paulista, Brasil Márcio de Vasconcellos Serelle, Pontifícia Universidade Católica de Minas Gerais, Brasil Maria Aparecida Baccega, Universidade de São Paulo e Escola Superior de Propaganda e Marketing, Brasi Maria das Graças Pinto Coelho, Universidade Federal do Rio Grande do Norte, Brasil Maria Immacolata Vassallo de Lopes, Universidade de São Paulo, Brasil Maria Luiza Martins de Mendonça, Universidade Federal de Goiás, Brasil Mauro de Souza Ventura, Universidade Estadual Paulista, Brasil Mauro Pereira Porto, Tulane University, Estados Unidos Nilda Aparecida Jacks, Universidade Federal do Rio Grande do Sul, Brasil Paulo Roberto Gibaldi Vaz, Universidade Federal do Rio de Janeiro, Brasil Potiguara Mendes Silveira Jr, Universidade Federal de Juiz de Fora, Brasil Renato Cordeiro Gomes, Pontifícia Universidade Católica do Rio de Janeiro, Brasil Robert K Logan, University of Toronto, Canadá

Ronaldo George Helal, Universidade do Estado do Rio de Janeiro, Brasil Rosana de Lima Soares, Universidade de São Paulo, Brasi Rose Melo Rocha, Escola Superior de Propaganda e Marketing, Brasil Rossana Reguillo, Instituto de Estudos Superiores do Ocidente, México Rousiley Celi Moreira Maia, Universidade Federal de Minas Gerais, Brasi Sebastião Carlos de Morais Squirra, Universidade Metodista de São Paulo, Brasil Sebastião Guilherme Albano da Costa, Universidade Federal do Rio Grande do Norte, Brasil

Simone Maria Andrade Pereira de Sá, Universidade Federal Fluminense, Brasi Suzete Venturelli, Universidade de Brasília, Brasil

Tiago Quiroga Fausto Neto, Universidade de Brasília, Brasil

Valerio Fuenzalida Fernández, Puc-Chile, Chile

Veneza Mayora Ronsini, Universidade Federal de Santa Maria, Brasi Vera Regina Veiga França, Universidade Federal de Minas Gerais, Brasil

\section{COMISSÃO EDITORIAL}

Cristiane Freitas Gutfreind I Pontifícia Universidade Católica do Rio Grande do Sul, Brasil Irene Machado I Universidade de São Paulo, Brasil

Jorge Cardoso Filho I Universidade Federal do Recôncavo da Bahia, Brasil Universidade Federal da Bahia, Brasil

CONSULTORES AD HOC

Adriana Amaral, Universidade do Vale do Rio dos Sinos, Brasil

Alexandre Rocha da Silva, Universidade Federal do Rio Grande do Sul, Brasi

Arthur Ituassu, Pontifícia Universidade Católica do Rio de Janeiro, Brasil

Bruno Souza Leal, Universidade Federal de Minas Gerais, Brasil

Elizabeth Bastos Duarte, Universidade Federal de Santa Maria, Brasil

Francisco Paulo Jamil Marques, Universidade Federal do Ceará, Brasi

Maurício Lissovsky, Universidade Federal do Rio de Janeiro, Brasil

Suzana Kilpp, Universidade do Vale do Rio dos Sinos, Brasil

Vander Casaqui, Escola Superior de Propaganda e Marketing, Brasi

EDIÇ̃̃O DE TEXTO E RESUMOS I Press Revisão

SECRETÁRIA EXECUTIVA I Helena Stigger

EDITORAÇÃo ELETRÔNICA I Roka Estúdio
COMPÓS I www.compos.org.br

Associação Nacional dos Programas de Pós-Graduação em Comunicação

Presidente

Eduardo Morettin

Universidade de São Paulo, Brasil

eduardomorettin@usp.br

Vice-presidente

Inês Vitorino

Universidade Federal do Ceará, Brasil

ines@ufc.br

Secretária-Geral

Gislene da Silva

Universidade Federal de Santa Catarina, Brasil

gislenedasilva@gmail.com 